\title{
A Review of Obstacles to Successful e-Learning Deployment in SMEs
}

\author{
Valéria Medárová ${ }^{1}$, Vladimír Bureš $^{2}$ and Tereza Otčenášková ${ }^{3}$ \\ ${ }^{1}$ College of Management, Bratislava, Slovakia \\ ${ }^{2}$ University of Hradec Králové, Hradec Králové, Czech Republic; College of Management, \\ Bratislava, Slovakia \\ ${ }^{3}$ University of Hradec Králové, Hradec Králové, Czech Republic
}

\begin{abstract}
E-Learning as an advanced form of learning supported by various technological principles and tools became a point of interest of both academicians and practitioners several years ago. Current literature contains mostly successful stories of its utilization in the business environment highlighting processes and decisions which should be done and make. Rarely are mentioned negative experiences related processes and decision that should not be realized. Hence, it is difficult to fully and explicitly define related bottlenecks or pitfalls. The aim of this paper is to assemble particular fragments and provide readers with a summary of general barriers of e-Learning implementation in small and medium-sized organizations together with recommendations how these barriers can be overcome. Therefore, this position paper provides basic literature overview of conditions and barriers to successful e-Learning implementation in the business settings. The investigation of published case studies reveals that there are several barriers, which need to be taken into the consideration to support fruitful usage of e-Learning technologies in the workplace. Furthermore, suggestions of potential activities that may contribute to coping with these barriers are depicted.
\end{abstract}

Keywords: small and medium-sized enterprises, e-Learning, employee education, workplace.

\section{Introduction}

E-learning as a modern approach to teaching and education of various types of students attracted the attention of specialists several years ago. The first studies can be traced back to 1990's (Mikulecký and Mikulecká, 1999). Consequently, e-Learning technologies and principles were more or less successfully introduced in several areas such as tourism (Čech and Bureš, 2009) or the business environment (Černá and Poulová, 2008; Mohelská, 2009). Their significance was emphasized by the
European Union (EU), which set a goal to make the European Union "the most competitive and dynamic knowledge-driven economy in the world" by "developing eLearning for all its citizens" at the Lisbon summit in 2000 (Cedefop, 2001). Clarke (2008) defines e-Learning as "learning through and being supported by the use of information technology". In the business setting, the importance of sharing information using information technology can be observed in concepts such as Human Resources Management, Knowledge Management, or Organizational

Copyright (C) 2012 Valéria Medárová, Vladimír Bureš and Tereza Otčenášková. This is an open access article distributed under the Creative Commons Attribution License unported 3.0, which permits unrestricted use, distribution, and reproduction in any medium, provided that original work is properly cited. Contact author: Vladimír Bureš E-mail: vladimir.bures@uhk.cz 
Development. All of them formalize access to knowledge and expertise, encourage high performance and innovation and support customer value (Bureš and Čech, 2007). The holistic approach to e-Learning makes this viewpoint even broader. In his framework Khan (2012) differentiates eight basic pillars of e-Learning - pedagogy, technology, interface design, evaluation, management, resource support, ethics, and institutional issues (see Figure 1). The objective of this paper is to review available papers focusing on these perspectives of e-Learning implementation in the business environment, to investigate the main conditions of successful e-Learning implementation, to identify main barriers, and to deduce proposals to overcome these barriers.

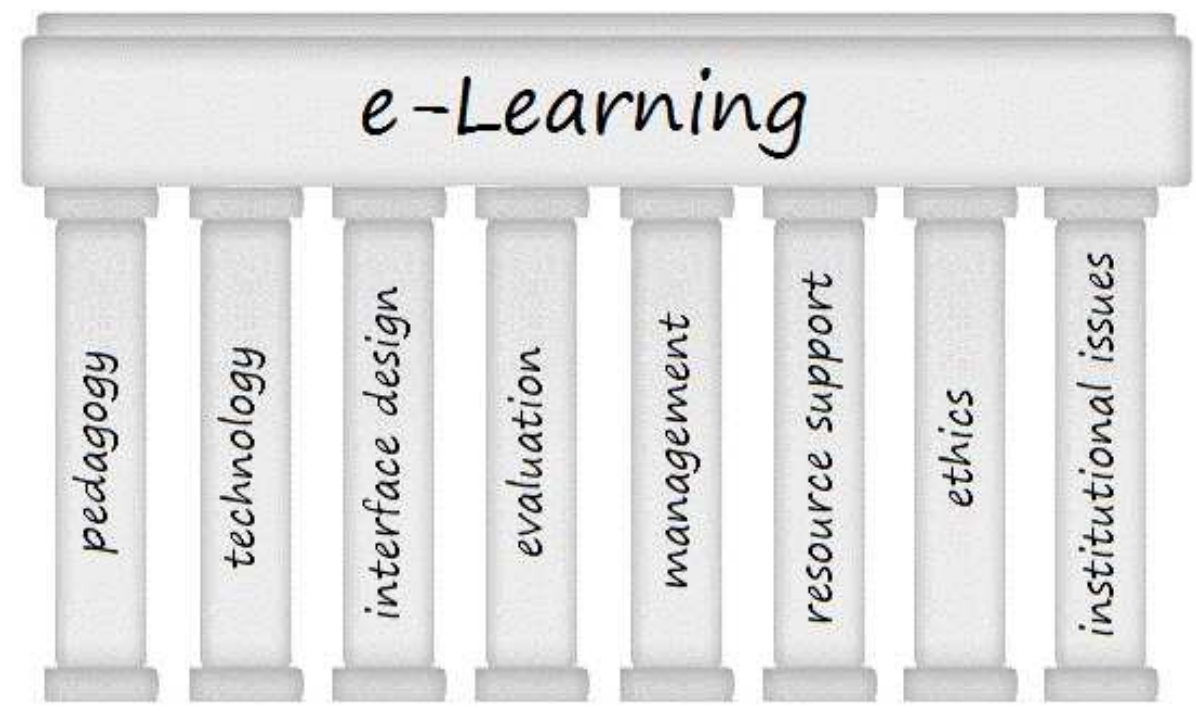

Fig 1. A Framework for e-Learning

\section{Methodology}

For the purpose of this study, the authors use the terms e-Learning and on-line learning as synonyms. According to Clarke, the terms eLearning and on-line learning are often used interchangeably and cover a wide range of approaches (2008). Available information on theoretical and practical aspects of eLearning application in small and mediumsized enterprises (SMEs) is explored. Relevant information is searched with the help of on-line scientific databases (ERIC, or EBSCO), e-publications, on-line journals, and books. The primary publication format used is a case study. However, several journal articles, conference papers, opinion papers, or instructional packets are included in the analysis. The search terms used are eLearning, on-line learning, employee education, training, and workplace. The publication date limitation is the years 20002012. The retrieved information is analysed in two stages and findings of various authors are compared. During the first stage the analysis is based on investigation of the content and identification of explicit as well as implicit barriers, which are experienced by authors. Consequently, the complete list is used for generalisation and classification of particular barriers. Moreover, the common and essential characteristics of the eLearning implementation are selected and summarized. The provided categorization of the common barriers to e-Learning implementation in the workplace is used for the second stage of the analysis, in which explicit and implicit lessons learned are enlisted. Hence, tools for avoiding the 
implementation barriers are summarized in the last section of the paper.

\section{Results}

Conditions of Successful Application of eLearning in the Workplace

The International Center for Learner Managed Learning at Middlesex University in London indicated 25 conditions of favorable learning environment in the workplace (Stephenson, 2003). For example, employees need to accept the organization's vision, see the connection between learning and performance, value knowledge as a means of development, have an active role in learning and feel valued by the organization. The company culture should support innovation, creativity, adaptability and cooperation. Managers should participate in the learning process, and learning effort should be officially recognized by the organization.

The SUPERSTELLA research project conducted in London in 1999-2001 revealed several major conditions of successful onthe-job on-line learning programs in SMEs (Stephenson, 2003). These programs should have flexible learning pace and duration and need to be adjusted to unexpected time constraints and resources of learners. Practical issues, mode of study and supposed outcomes should be clearly explained. Learning support should be provided by proactive on-line supervisors and via working relationships. Also, learners should have a possibility to withdraw from the course if needed.

Moses (2001) describes new needs of webbased operating firms - enterprise resource planning and customer relationship management, which lead to the need to upgrade the workforce. This goal can be achieved by on-line employee training. Moses lists the main advantages of e-Learning in the workplace (based on A. W. Bates' taxonomy of open learning): an appropriate level and access for learners, cost efficiency, suitable learning styles, an interactive and user friendly approach, appropriate organization, interesting and motivating design, an adjustable format, fast delivery.

As stated by Schreurs, Sammour and Ehlers (2008) organizations have to make sure they are ready to implement e-Learning. They should determine the level of their "eLearning readiness" prior to the implementation. E-readiness presents ability of learners to use technology, to cooperate, to learn both synchronously and asynchronously, to be motivated and selfdisciplined; an e-ready organization should have the necessary infrastructure, clear eLearning goals, learner support and knowledgeable management.

\section{Barriers to e-Learning in the Workplace}

The SUPERSTELLA study lists major barriers to employee learning. According to the research outcomes, work deadlines take preference over learning/training; time and space available for workplace learning programs as well as the number of substitute staff is limited. Managers are not adequately involved in the employee training. Also, the initial cost of computer and information technology is high (Stephenson, 2003).

In a case study of the U.S. Army workplace, Finley (2000) presented possibilities and constraints of on-line learning - specifically in the work team of 13 employees at the U.S. Army's Armored Office Research Unit. The purpose of the study was to analyze how online learning can serve self-development needs of behavioral research workers of the army forces. The areas in which the team needed to increase their qualifications were: HR administration, new software programs, statistical analysis, training, and decision sciences. The major constraints of on-line learning in the workplace in the studied unit were time constraints and the Internet accessibility during peak usage hours. The available time was limited, and work schedules of the employees were unpredictable. The time constraint depended on the nature of the on-line course, 
specifically on the institutional and administrative conditions of the organization providing the course, dedication and work contract conditions of the course instructor, and the number of assignments which involve cooperation with the teacher and/or classmates. The Internet infrastructure is a crucial component of the armed forces workplaces. Therefore, when the usage of the Internet increased during work hours, it affected other departments as well. Finley concludes that for the purposes of the given army institution, web-based courses available at the time of the research could be useful only to a certain extent, and in the future there should be a possibility of webbased short seminars conducted by an instructor and lasting the total of 8-16 hours with active student participation.

Deall (2002) states several major obstacles to on-line learning in the university environment. The major barrier categories are low Internet connectivity, insufficient technical equipment, and low distance learning skills. Specifically, huge discrepancies may appear between courses developed using high-end computer technology and fast Internet connection on one side, and learners using basic hardware and slow Internet connection on the other. As an example, courses with audio and video materials may frustrate students using dialup connection. Therefore, specific requirements on hardware, software and Internet speed should be defined at the beginning of the course and the learners should comply with them. Many distance learning courses require $56 \mathrm{~K}$ dial-up connection or broadband connection as well as SW programs such as Flash, Shockwave, Acrobat reader, Real Audio player, etc. As has been stated, learners lacking unique distance learning skills present another obstacle. "Not all learning styles and personalities are suited to a distance learning format." (Deall, 2002) Learners with no or limited writing and communication skills, organization and time management skills or ability to learn independently may experience difficulties in the learning process. Also, learners need to have the so-called "electronic team skills", because team members are separated by time and distance.

A case study of Newton and Ellis (2005) identifies factors that impact e-Learning in the Australian army environment. The most important factors are "drivers for change, training culture, learner needs". The authors state that the working environment of the Australian army changes constantly, e.g. there are frequent staff changes. The related obstacle was that implementation of eLearning often depended on a few individuals who were not working in the same workplace, and it often lacked centralized funding. Due to frequent movements of the staff, the projects lacked sustainability. The case study demonstrated technical and logistical limitations of the eLearning program. The design and delivery of the courses was consistent only with the technical and operational conditions of the Army, so at the beginning the management did not try to create a networked learning environment. An example is the fact that soldiers spent a big portion of the year in training fields without access to the Internet or Intranet. Also, the available network restricted design of instructional tools. Another potential barrier to e-Learning, according to managers interviewed by Newton and Ellis, was the need for trainees to be appropriately re-socialized according to specifics of a given culture (Newton and Ellis, 2005). The interviewed course instructors found out that the e-Learning courses did not recognize diversity of learners. The reason was that managers considered individualization of e-Learning too expensive. The learners had diverse computer skills, and some of them needed several days to learn to work with navigation systems.

Finally, Weaver (2002) lists 10 major pitfalls of e-Learning in organizations:

Assuming that e-Learning is a cheaper alternative to training in the workplace: Managers often overlook costs related to 
planning, installation, integration of systems and marketing, in addition to the cost of the actual course content. Implementing e-Learning is investment.

\section{- Overestimating what e-Learning can accomplish: e-Learning will never substitute instructor-led training} completely because people are social learners and as such, they need face-to-face interaction and sharing of ideas in groups, which the Web cannot provide.

\section{- Ignoring shortcomings of self-study:} Learners can adjust the schedule of study but if they are not motivated, they may not complete the course. Research shows that on-line learners do not complete 50-90 per cent of on-line courses. The actual time of learning is a problem too - learners are often not motivated to attend courses in addition to their full work load; on the other hand, managers are often not motivated to implement on-line learning if there is a threat of work productivity decrease.

\section{Failing to look beyond course paradigm:} There is a belief that e-Learning is related just to the actual course content. However, the Internet and Intranet enable many eLearning tools which should not be ignored. For instance, e-mail discussions, chat rooms, small group projects, knowledge management systems or even phone conferences can be incorporated in the course design.

- Viewing content as a commodity: Some on-line courses do not have the appropriate or effective content if they ignore specific needs of the organization's training program and of the target audience (e.g. from the cultural and geographical point of view), or if they are simply not designed professionally.

- Ignoring technology: It is a mistake to ignore importance of purchasing the proper technical equipment. Adequate operating systems, Web browsers, learning management systems, databases, and other tools should be utilized.

- Failing to involve IT staff: Failure to consult IT specialists early in the process of e-Learning implementation may lead to the situation that the purchased e-Learning system is incompatible with the organization's computer system.

- Fixating too much on technology: It is necessary to realize that e-Learning impacts people working in the organization and that its main goal is change of the organization, which can cause resentment because people in general do not like change. Therefore, they should be involved in the process early and their feedback and opinions should be considered.

\section{- Assuming that learned knowledge will be applied: Learners need to have suitable conditions to apply their new skills. Otherwise, they will not feel comfortable using them. \\ - Believing that because you implement e-Learning, employees will use it: If on- line training does not meet the projected goals, the resources are wasted. The reasons include poor content of the course and its inadequate implementation, lack of management support, low motivation, etc.}

\section{Classification of Barriers}

The researched information from various sources provides some overlapping characteristics of e-Learning programs in various workplaces and several common barriers to implementation of e-Learning. The analyzed experience comes from various work environments, such as SMEs, military units, and colleges. All the cited studies emphasize efficiency and importance of incorporating e-Learning in training and education. The obstacles to successful implementation of e-Learning in the workplace can be divided into the following categories. 
Conceptual barriers present two main groups of obstacles - misunderstanding of the purpose of e-Learning and failure to align the e-Learning system with the organization's needs and target users. That means that the e-Learning system is not selected properly and it does not match the needs of the organization, or it is simply overestimated. Next, the course content may not match the target audience and the organization's needs or is not designed properly and professionally. Also, too much or too little emphasis on technical aspects can be a disadvantage as several authors have stated.

Organizational barriers can be divided into several sub-categories: poor planning, ineffective communication between all the involved parties, insufficient funding, poor control of the system's functioning and failure to apply the learned skills in the workplace. Planning involves proper preparation, scheduling, time management and promotion of e-Learning implementation in the organization. Also, sufficient time has to be provided for the actual learning process. Failure to assign responsible staff and ineffective communication between them may cause difficulties and discrepancies in the implementation and operations of the system. Lack of a separate e-learning budget may lead to inability to obtain the necessary technical equipment, to finance the course development, to hire eLearning and information and communication technologies (ICT) experts, etc. Another barrier is lack of continuous control of the system's functioning and lack of user feedback collection, because they are necessary to achieve successful implementation and improvement of the system. Finally, if the learned skills are not applied in the workplace, the invested effort and resources are wasted.

Technical barriers include inadequate information and communication technology (hardware not meeting the system requirements, poor Internet connectivity, inadequate or incompatible software components), poor quality of instructional media, neglected technical update and lacking technical support, etc.

The human factor barriers can be divided into two main sub-categories - individual and social. The individual human factor relates to the approach of an individual to the whole e-Learning concept, system and tools, while the social human factor deals with relations and communication between users of e-Learning systems. The communicating groups include: the orga nization's managers, the e-Learning training program developers/designers, technical and IT support staff, end users of the system (mainly instructors/tutors and learners). The obstacles experienced by all these groups include lack of motivation, insufficient knowledge of the e-Learning program concept and of the organization's needs, insufficient involvement and effort, and poor communication, ICT and learning skills.

All the described e-Learning barriers are interconnected and one may lead to another, e.g. poor organization of e-Learning may lead to technical problems and decreased learners' motivation, which in turn may lead to failure to meet the organization's goals, etc. (see Figure 2). 


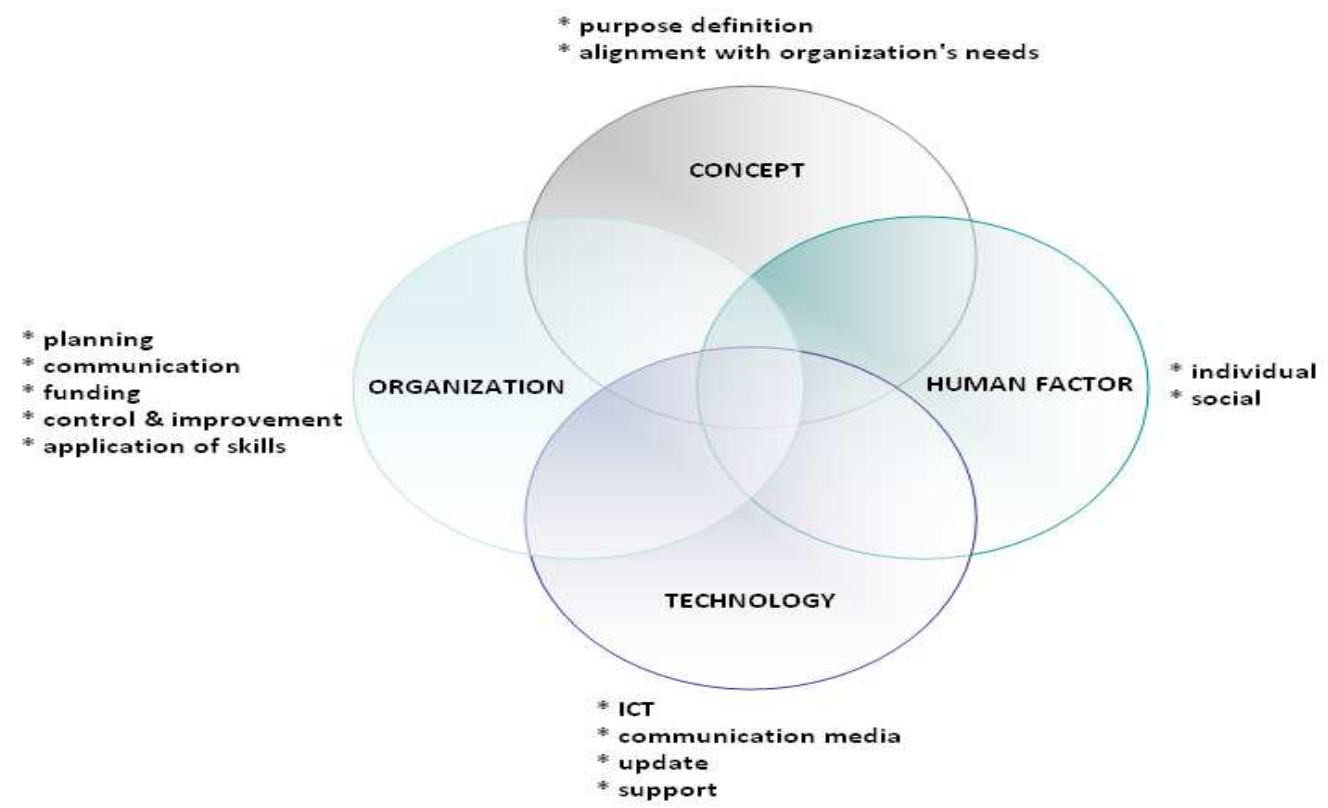

Fig 2. Areas of Potential Barriers to Implementation of e-Learning

\section{How to Avoid Barriers}

Based on the reviewed literature and research outcomes mentioned in previous paragraphs, the authors of the paper provide readers with a summary of major prerequisites of successful implementation of e-Learning in the workplace:

- An organization should evaluate the actual need to implement the eLearning program and its justification (potential to increase performance, cost efficiency, future benefits, etc.). An organization should conduct a detailed study of its vision, objective, and learning needs and how e-Learning can fulfill these needs. Next, it should select the suitable eLearning program. An e-Learning system management team should be appointed, with responsibility for proper planning, design and control of the system implementation.

- Implementation of e-Learning programs should be funded adequately. A separate budget should be designed for planning, design, support, and management of the implementation.

- The selected technical equipment, hardware and software tools as well content-based design should match the needs of the organization and its employees. Hardware, software, and the course content for the e-Learning system should be selected carefully, according to the strategic e-Learning implementation plan, with the use of the assigned budget. The course content should be designed by experts who should be informed of the eLearning purpose and requirements in detail.

- All the competent staff members should be involved in the preparation of the training program. They should communicate with each other actively and on regular basis - before, during, and after implementation of the e-Learning process. Arising problems and issues should be communicated in timely manner in order to find right solutions and incorporate them in the implementation process. 
- Installation of the system should be conducted in a time-efficient manner. The preparation process should include a project plan with a detailed schedule of all the steps of the implementation, with enough time allocated to each step, taking into consideration potential difficulties and delays.

- The training program should be explained and promoted properly to all the stakeholders, i.e. managers, implementation team members, IT staff, employees (end users), etc. Proper and timely presentation (marketing) of the eLearning system's purpose and value (both for individual employees and for the organization as a whole) can motivate the stakeholders and eliminate potential refusal to participate as the reviewed research outcomes suggest.

\section{- Sufficient time and work conditions should be provided to the end users of the e-Learning training program. According to the reviewed literature, e- Learning programs do not serve their purpose if they are not incorporated efficiently in the workload of learners (the organization's employees) and if the learners do not have time to participate in e-Learning training.}

- Technical support and service should be available at all times. The actual creation and installation of an e-Learning system is not sufficient to achieve successful learning. Many technical, logistical and organizational issues may come up during the whole process of using the system. Therefore, it is necessary to provide constant technical help and service if problems emerge. Responsible staff should be appointed to provide assistance.

\footnotetext{
- Regular evaluation of the training program and of its organizational and technical aspects should be conducted. Feedback from all the stakeholders and lessons learned should be collected and incorporated in the improvement process.
}

A responsible team should be appointed that will conduct this formal evaluation via performance analysis, statistical data, questionnaires, reports from the technical support staff, etc.

\section{Conclusions}

Implementation of e-Learning has its important place in business. It is an on-going process. As such, it does not start and end with the actual technical installation and providing the training courses. The outcomes and lessons learned should be constantly used to improve and innovate the whole system for better future utilisation. At this point, it is hard to say which of the eLearning barriers is predominant. The correct understanding of the concept of eLearning is essential and all other processes stem from its definition in a particular organization in the first place. However, each component (conceptual, organizational, technical, and human) influences the others significantly. Further study is needed in this area to find out how exactly these components are interconnected and especially how the human factor impacts success of e-Learning in an organization. Case studies and practical examples of eLearning implementation may bring more light on these issues.

\section{Acknowledgment}

This paper was created with the support of the ESF project INDOP - Innovation and Support of the Doctoral Study Program, identification number CZ.1.07/2.2.00/28.0327.

\section{References}

Bureš, V. \& Čech, P. (2007). 'Knowledge Intensity of Organizations in Knowledge Economy,' Proceedings of the 3rd International Conference on Web Information Systems and Technologies, Barcelona, Spain, 210-213. 
9 Journal of Innovation Management in Small \& Medium Enterprises

Čech, P. \& Bureš, V. (2009). "Advanced Technologies in e-Tourism," 9th WSEAS International Conference on Applied Computer Science, Genova, Italy, 85-92.

Cedefop (2001). E-learning and Training in Europe, Cedefop Reference Series, Office for Official Publications of the European Communities, Luxembourg.

Černá, M. \& Poulová, P. (2008). 'Visit Rate of Internet Portals and Utilization of Their Tools and Services,' E+M Ekonomie a Management, 11 (4), 132-143.

Clarke, A. (2008). E-Learning Skills, Palgrave Macmillan, New York.

Deall, W. F. (2002). "Distance Learning: Teaching Technology Online," The Technology Teacher, May/June, 21-26.

Finley, D. L. (2000). "Online Education as a Means for Workplace Learning: A Case Study," Annual Meeting of the American Educational Research Association, New Orleans, LS, 1-7.

Khan, B. (2012). E-learning Framework. [Online], [Retrieved April 20, 2012], http://asianvu.com/bk/framework/.

Publisher

Mikulecký, P. \& Mikulecká, J. (1999). “Active Tools for Better Knowledge Dissemination," Proceedings of the 62nd ASIS Annual Meeting, Washington, D.C., 420-427.

Mohelská, H. (2009). 'Value of ICT Mobile Means in an Increase of Company Competitiveness,' World Multiconference on Applied Economics, Business and Development, Tenerife, Spain, 137-140.

Moses, K. D. (2001). 'The Role of e-Learning in Training and Development,' TechKnowLogia, 3 (3), 13-14.
Newton, D. \& Ellis, A. (2005). "Effective Implementation of e-Learning: A Case Study of the Australian Army," Southern Cross University ePublications@SCU. [Online], [Retrieved January 28, 2012], http://epubs.scu.edu.au/tlc_pubs/l/.

Schreurs, J., Sammour, G. \& Ehlers, U. (2008). "ERA - E-learning Readiness Analysis: An eHealth Case Study of e-Learning Readiness," Lytras, M. D., Carroll, J. M., Damiani, E., Tennyson, R. D., Avison, D., Vossen, G. and Ordóñez de Pablos, P. (eds), The open knowledge society. A Computer Science and Information System Manifesto, SpringerVerlag, Heidelberg, 267-275.

Stephenson, J. (2003). “A Review of Research and Practice in e-Learning in the Workplace and Proposals for Its Effective Use," Annual Meeting of the American Educational Research Association, Chicago, IL, 21-25.

Weaver, P. (2002). "Preventing e-Learning Failures: Ten Common Pitfalls and How to Avoid Them," American Society for Training and Development. [Online], [Retrieved January 28, 2012], http://findarticles.com/p/articles/mi_m0MN T/is_8_56/ai_90512523/?tag=content;col1.

Whiteman, J. A. M. (2001). "Relevance of Education \& Training in a Business Environment,". [Online], [Retrieved January 28, 2012], http://www.eric.ed.gov/PDFS/ED455419.pd $\mathrm{f}$ 